Article

\title{
Green Bio-Assisted Synthesis, Characterization and Biological Evaluation of Biocompatible ZnO NPs Synthesized from Different Tissues of Milk Thistle (Silybum marianum)
}

\author{
Bilal Haider Abbasi ${ }^{1, *} \mathbb{0}$, Muzamil Shah ${ }^{1}$, Syed Salman Hashmi ${ }^{1}$, Munazza Nazir ${ }^{1,2}$, \\ Sania Naz ${ }^{1}$, Waqar Ahmad ${ }^{3}$, Inam Ullah Khan ${ }^{4}$ and Christophe Hano ${ }^{5, *}$ (i) \\ 1 Department of Biotechnology, Quaid I Azam University, Islamabad 45320, Pakistan \\ 2 Department of Botany, University of Azad Jammu \& Kashmir, Muzaffarabad 13230, Pakistan \\ 3 Department of Pharmacy, Quaid I Azam University, Islamabad 45320, Pakistan \\ 4 Department of Biochemistry, Quaid I Azam University, Islamabad 45320, Pakistan \\ 5 Laboratoire de Biologie des Ligneux et des Grandes Cultures (LBLGC), INRA USC1328, \\ Université d'Orléans, F28000 Chartres, France \\ * Correspondence: bhabbasi@qau.edu.pk (B.H.A.); christophe.hano@univ-orleans.fr or \\ hano@univ-orleans.fr (C.H.); Tel./Fax: +33-77-698-41-48 (B.H.A.); +33-237-309-753 (C.H.)
}

Received: 12 July 2019; Accepted: 13 August 2019; Published: 16 August 2019

check for updates

\begin{abstract}
The purpose of the current study was green synthesis of ZnO-nanoparticles (NPs) from different tissues of Silybum marianum (L.) Gaernt. (i.e., seeds, wild plant, in vitro derived plantlets and callus cultures) followed by extensive characterization and evaluation of their biological potency. ZnO-NPs thus synthesized were subjected to characterization using standard techniques such as XRD, FTIR and SEM. Thermal stability of synthesized NPs was also evaluated using thermo-gravimetric analysis. Highly stable crystalline NPs with size ranging between 30.8 and $46.0 \mathrm{~nm}$ were obtained from different tissues of S. marianum. These NPs have revealed a wide range of biological applications showing antioxidant, moderate $\alpha$-amylase inhibitor, antibacterial and cytotoxic potencies. The highest antibacterial activity $(20 \pm 0.98 \mathrm{~mm})$ was shown by seed extract-mediated ZnO NPs against Staphylococcus aureus (ATCC-6538). Seed extract-mediated ZnO NPs also showed the most potent antioxidant activity $(27.7 \pm 0.9 \mu \mathrm{gAAE} / \mathrm{mg}, 23.8 \pm 0.7 \mu \mathrm{gAAE} / \mathrm{mg}$ and $12.7 \pm 1.9 \%$ total antioxidant capacity (TAC), total reducing power (TRP) and DPPH-free radical scavenging assay (FRSA), respectively). All of the synthesized ZnO NPs also showed cytotoxic activity against the hepato-cellular carcinoma (HepG2) human cells. Interestingly, these ZnO NPs were also highly biocompatible, as evidenced by the brine shrimp lethality and human red blood cells hemolytic assays. Among all of the NPs synthesized and used, the effect of seed extract-mediated NPs was found to be most promising for future applications.
\end{abstract}

Keywords: Zinc Oxide (ZnO); Nanoparticles (NPs); characterization; Silybum marianum; in vitro plantlets; cytotoxic assay; green synthesis

\section{Introduction}

One of the most promising areas of research that has emerged in science and technology is "Nanotechnology", which has introduced a global paradigm shift in life sciences [1]. Nanotechnology has brought about revolutionary transformation in domains ranging from health to industrial materials. The key product of nanotechnology, i.e., nanoparticles (NPs) can be defined as materials that possess at least a unit dimension in the nanometer range $(1-100 \mathrm{~nm})$ [2]. In order to formulate these NPs, 
the biological route has received much more attention due to several important attributes such as safety, environmentally friendly protocols with non-toxic byproducts, gentle reaction condition requirements and the use of natural capping and reducing agents [3]. The NPs thus produced through the biological approach are comparatively stable and safer, with much more diversity in terms of size and shape [4]. The most abundantly used biological route for NPs synthesis is the use of plant extracts for the formulation of ecofriendly NPs, which cuts out the use of noxious chemicals with toxic effects [5]. Plant-mediated NPs synthesis results in the formulation of NPs having definite shape and size. Researchers are also working on the use of the aqueous medium containing hydrolytic reagents for possible capping and stabilization of materials in the nanodimension [6].

The interdisciplinary link between nanotechnology and biotechnology gives rise to a new discipline, namely nanobiotechnology, which specifically deals with production, enhanced potential and utilization of material at the nanoscale for advanced research [7]. The focus of nanobiotechnology is to promote the use of economical and environmentally benign reducing and capping agents obtained from living material such as fungi, microbes, algae and plant material (including tissues, seeds and fruits, etc.) for their feasible use in medicinal compounds, cosmetic industries and water disinfection [8]. The adverse effects of NPs are neutralized due to the presence of natural metabolites in plants and other biological materials [9]. NPs produced as a result of green approaches are the center of consideration in various fields including synthetic chemistry, biotechnology, environmental sciences and biochemistry.

Zinc oxide $(\mathrm{ZnO})$ biosynthesized nanocomposites have unique features. A number of researchers have found it attractive for research in multiple research disciplines due to the novel applications. Some of the important features of $\mathrm{ZnO}$ includes piezoelectric, catalytic pyroelectric, optoelectronics and semiconducting capacity [10]. It is an n-type semi-conductor having exciton binding energy of $60 \mathrm{meV}$, and its energy of band gap at the normal room temperature is $3.37 \mathrm{eV}$. The nanostructured form of $\mathrm{ZnO}$ further adds to its physio-chemical properties due to the increased ratio of surface-to-volume. In order to bring $\mathrm{ZnO}$ particles into the nanoscale, a variety of protocols can be utilized which includes the vapor-liquid-solid (VLS) [11], hydrothermal synthesis [12], vapor phase deposition [13], chemical vapor deposition [14], metallo-organic deposition of chemical vapors [15] and zinc oxidation [16]. ZnO NPs with several different morphologies including NPs [17], nanorods [18], nanowire [19], nanobelts [20], nanoflowers [21] and nanoflakes [22] have been synthesized using the aforementioned techniques. Such conventional techniques have several limitations which make their use questionable, and hence, green synthesis has proven an effective alternate for the synthesis of ZnO NPs in order to overcome the issues mentioned earlier [23-25].

Several NPs have been evaluated for their potential applications out of which Zinc Oxide ( $\mathrm{ZnO})$ NPs have proved to be a vital alternative for remediation of pollutants in the environment, owing to their high absorption capacity for UV rays. ZnO NPs have also been reported to result in elevated production of reactive oxygen species (ROS), including hydrogen peroxides [6,26,27]. Their applications in the semiconductors industry for the production of solar cells are also well documented [28-30]. The distinctive photochemical, antifungal, antibacterial, catalytic and UV-filtering potential of $\mathrm{ZnO}$ NPs has brought them into the limelight for interdisciplinary research [31]. ZnO NPs have also shown great promise in solar cell industries, displays, bio-sensors, photo-catalysis, pharmaceutical and cosmetic industries [32-34]. A variety of plant species have been efficiently used for the reduction and capping of ZnO NPs including Aloe vera [7,35], Calotropis gigantea [36], Citrus aurantifolia fruits [37], Coriandrum sativum [38], Parthenium hysterophorus L. [39] or milky latex of Calotropis procera [40].

The current research focuses on ZnO NPs phyto-synthesis using various extracts of Silybum marianum (L.) Gaernt. (Milk thistle) (seeds, wild plant, in vitro derived callus and plantlets). Different biological assays, including antioxidant, antibacterial, antiproliferative assays, together with brine shrimp lethality and human red blood cells hemolytic assays, were conducted to test the potency of synthesized NPs and study whether the different bioresources of the same plant have any impact on NPs synthesis, morphology, size and the ZnO NPs activity. 


\section{Materials and Methods}

\subsection{Seeds Collection}

Silybum marianum (L.) Gaernt. (Milk thistle) seeds plants were collected from Khyber Pukhtoonkhawa, Peshawar, KP. The wild plants used in the study were sampled from Quaid-i-Azam University, Islamabad.

\subsection{Reagents}

All of the chemicals used in the present study, and in particular, the zinc acetate dihydrate, were obtained from the Sigma-Aldrich Company (Sigma-Aldrich, Saint-Quentin Fallavier, France).

\subsection{Preparation of Plant Extract}

Plant extract was prepared by mixing the respective plant material (seeds, wild plant in vitro derived plantlets and callus) with distilled water in a 1:10 ratio into an Erlenmeyer flask containing $15 \mathrm{~g}$ of plant material for $150 \mathrm{~mL}$ distilled water. The callus for biosynthesis of ZnO NPs was obtained by inoculating the explant at a hormonal concentration of $0.5 \mathrm{mg} / \mathrm{L} \mathrm{BAP} \mathrm{(6-benzylaminopurine)} \mathrm{and}$ $1 \mathrm{mg} / \mathrm{L}$ of 1-NAA (1-naphthaleneacetic acid) to induce callus culture. Harvesting of the callus was done after 28 days. The seeds were grinded while the rest of the plant materials were chopped into fine pieces prior to mixing. The resulting mixtures, in the case of seeds, wild plant and in vitro derived plantlets, were boiled for $2 \mathrm{~h}$ at $100{ }^{\circ} \mathrm{C}$. The boiled mixture was then incubated at $40{ }^{\circ} \mathrm{C}$ overnight. The flask containing callus was placed in a shaker incubator for $24 \mathrm{~h}$ instead of heating. The extracts were then filtered and kept in a refrigerator prior to their use.

\subsection{ZnO NPs Biosynthesis}

$\mathrm{ZnO}$ NPs biosynthesis was carried out by adding zinc acetate di-hydrate (molecular weight: $219.51 \mathrm{~g} / \mathrm{mol}$ ) to the plant extract in a 100:1 ratio comprising $1 \mathrm{mM}$ of zinc acetate di-hydrate into $100 \mathrm{~mL}$ of plant extract. The $\mathrm{pH}$ was set at 12 and the extract was then kept for $24 \mathrm{~h}$ at $37^{\circ} \mathrm{C}$. After $24 \mathrm{~h}$, $\mathrm{ZnO}$ NPs gathered at the base of the Erlenmeyer flask. The supernatant was discarded and the solution containing NPs was introduced into $1.5 \mathrm{~mL}$ microcentrifuge tubes and washed with $1 \mathrm{~mL}$ of pure ethanol keeping centrifuge for $10 \mathrm{~min}$ at $12,000 \mathrm{rpm}$. The supernatant was disposed of and the left-over pellets were washed thrice with the distilled water. Calcination $\left(500{ }^{\circ} \mathrm{C}\right)$ of the NPs was done for $2 \mathrm{~h}$ to increase the crystallinity of the NPs.

\subsection{Characterization}

To confirm the biosynthesis and crystallinity of the ZnO NPs, they were subjected to X-ray Diffraction (XRD) (Model-D8 Advance, Bruker, Mannheim, Germany).

For size and morphological analysis, scanning electron microscopy (SEM) was carried out by using JEOL-JSM-6490LA SEM (JEOL, Tokyo, Japan). Instrument works at $20 \mathrm{kV}$ with 2838 counts per second.

Fourier transform infrared (FTIR) spectroscopy (SHIMADZU 8100 M FTIR, Shimadzu, Kyoto, Japan) was done to study the presence of bio-molecules as capping agents on ZnO NPs surface in the range of $400-4000 \mathrm{~cm}^{-1}$.

For determination of thermal stability, thermo-gravimetric analysis (TGA) was conducted. The samples were studied at a temperature ranging from 0 to $1100{ }^{\circ} \mathrm{C}$ under a nitrogen atmosphere with an increase of $10^{\circ} \mathrm{C} / \mathrm{min}$ using TGA (TGA/DSC1, Star e System, Mettler Toledo, Giessen, Germany).

\subsection{MTT Assay}

\subsubsection{Cell Culture}

Human hepato-cellular carcinoma cells HepG2 (ATCC HB-8065; American Type Culture Collection, Manassas, VA, USA) were cultured in Dulbecco's Modified Eagle Medium (DMEM) comprising of 
$10 \%$ fetal calf serum (FCS), supplemented with $2 \mathrm{mM} \mathrm{L-glutamine,} 100 \mathrm{U} / \mathrm{mL}$ penicillin, $100 \mu \mathrm{g} / \mathrm{mL}$ streptomycin, $1 \mathrm{mM}$ Na-pyruvate at $37^{\circ} \mathrm{C}$ in a humidified $5 \%$ atmosphere of $\mathrm{CO}_{2}$. Cell harvesting was carried out using $0.5 \mathrm{mM}$ trypsin/EDTA for $1 \mathrm{~min}$ at room temperature $\left(25 \pm 1^{\circ} \mathrm{C}\right)$.

\subsubsection{Evaluation of Mitochondrial Function using Cytotoxicity Analysis: MTT Assay}

MTT (3-(4,5-dimethylthiazolyl-2)-2,5-diphenyltetrazolium bromide), a tetrazolium dye was used to access cytotoxic potential of extracts/NPs in vitro. In living cells, MTT is reduced into its insoluble purple product formazan which is measured spectrophotometrically.

In a 96-well plate, pre-seeded HepG2 cells (>90\% viability; $1 \times 10^{4}$ cells/well; $200 \mu \mathrm{L}$ per well) were treated with $200 \mu \mathrm{g} / \mathrm{mL}$ of test samples for $24 \mathrm{~h}$. Later, $10 \mu \mathrm{L}$ of MTT dye $(5 \mathrm{mg} / \mathrm{mL})$ was added per well, followed by incubation of $3 \mathrm{~h}$. Insoluble formazan was then dissolved by adding $10 \%$ acidified sodium dodecyl sulfate (SDS). Cells were then incubated overnight. Plates were analyzed at $570 \mathrm{~nm}$ using a microplate reader (Platos R, 496. AMP, AMEDA Labordiagnostik GmbH, Graz, Austria).

Untreated HepG2 cells (NTC) were included as controls. DMSO was used as negative control for plant extracts. NPs were sonicated (ultrasonic bath USC1200TH, Prolabo, Sion, Switzerland) prior to cytotoxicity screening and the extracts were centrifuged prior to cytotoxicity screening percent (\%) viability being quantified with respect to the NTC sample, using the following equation:

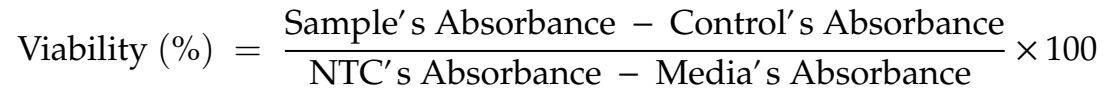

where Abs. of NTC and Abs. of sample corresponds to the optical density at $570 \mathrm{~nm}$ respectively for the untreated control samples and treated control samples. Abs of blank and Abs. of sample control corresponds to background optical density. This was quantified in media samples and NPs/extracts only.

For each sample, the experiment was performed twice with three replicates.

\subsection{Antibacterial Potency}

Synthesized NPs were evaluated for their antibacterial potency through disc diffusion assay according to established protocol with slight modification [41,42]. Refreshed bacterial cultures of gram positive, i.e., Staphylococcus aureus (ATCC-6538) and Bacillus subtilis (ATCC-6633) bacterial strains, and gram negative, i.e., Escherichia coli (ATCC-25922), Pseudomonas aeruginosa (ATCC-15442) and Klebsiella pneumonia (ATCC-1705) bacterial strains, with pre-adjusted seeding density, were prepared. A total of $5 \mu \mathrm{L}$ of each sample was introduced on sterile disks placed on specific sites on agar seeded plates. Cefixime and roxithromycin acted as a positive control, while DMSO was used as a negative control. The plates were then incubated for a period of $24 \mathrm{~h}$ at $37^{\circ} \mathrm{C}$. Following incubation, the zones of inhibition for all of the test samples were measured and recorded. Test samples showing a zone of inhibition $\geq 12 \mathrm{~mm}$ were scrutinized to ascertain MIC (minimum inhibitory concentration) using the standard three-fold micro-broth dilution.

Stock solutions (20 mg/mL in DMSO) of each of the synthesized $\mathrm{ZnO}$ nanoparticle was diluted serially in a 96-well microtiter plate $(200 \mu \mathrm{L}$ per well) with Mueller Hinton broth to reach the range of concentration from $3.70 \mu \mathrm{g} / \mathrm{mL}$ up to $100 \mu \mathrm{g} / \mathrm{mL}$. A standardized inoculum for each bacterial strain was prepared in order to permit the size of inoculum equaling $5 \times 10^{6} \mathrm{CFU} / \mathrm{mL}$ (colony forming unit) approximately in each well. The plates prepared were then incubated overnight at $37^{\circ} \mathrm{C}$. After completion of incubation period, the MIC was evaluated as the lowest concentration of the test extract inhibiting the bacterial strain growth by measuring optical density (OD) at $630 \mathrm{~nm}$, using a microplate reader (Platos R, 496. AMP, AMEDA Labordiagnostik GmbH, Graz, Austria). All of the test NPs were evaluated in triplicate.

\subsection{Total Antioxidant Capacity (TAC)}

The assessment of the total antioxidant capacity of the NPs was carried out using a phosphomolybdenum-based assay [42,43]. The test sample (4 mg/mL dissolved in DMSO) and 
DMSO (negative control) amounting $100 \mu \mathrm{L}$ were separately added to $900 \mu \mathrm{L}$ reagent containing sulfuric acid, ammonium molybdate and sodium phosphate having concentrations of $0.6 \mathrm{M}, 4 \mathrm{mM}$ and $28 \mathrm{mM}$, respectively. The resulting mixture was subjected to incubation in a water bath for $90 \mathrm{~min}$ at $95{ }^{\circ} \mathrm{C}$ so as to complete the reaction. The absorbance of standard and test solutions was recorded at $695 \mathrm{~nm}$ once it cooled down via PDA spectrophotometer (8354 Agilent Technologies, Waldbronn, Germany). For a blank reading, DMSO was used. The same experiment for the total antioxidant capacity (TAC) was done in triplicate. The antioxidant activity evaluated corresponds to $\mu \mathrm{g} / \mathrm{mg} \mathrm{dry}$ weight of ascorbic acid equivalent antioxidant capacity ( $\mu \mathrm{g}$ AAE/mg DW).

\subsection{Total Reducing Power (TRP)}

To calculate the reducing power of different NPs, potassium ferricyanide colorimetric assay was used [41-43]. A total of $400 \mu \mathrm{L}$ of ferricyanide (1\%) in $0.2 \mathrm{~mol} / \mathrm{L}$ phosphate buffer (pH 6.6) and $100 \mu \mathrm{L}$ of test sample ( $4 \mathrm{mg} / \mathrm{mL}$ dissolved in DMSO) were combined. The resulting mixture was then incubated at $50{ }^{\circ} \mathrm{C}$ for $20 \mathrm{~min}$. A total of $400 \mu \mathrm{L}$ of trichloroacetic acid (10\%) was added to each sample after incubation. The resulting mixture was then centrifuged at room temperature for $10 \mathrm{~min}$ at $3000 \mathrm{rpm}$. A total of $500 \mu \mathrm{L}$ of the supernatant was collected, to which $100 \mu \mathrm{L}$ of $0.1 \% \mathrm{FeCl}_{3}$ and $500 \mu \mathrm{L}$ of distilled water were added. Finally, optical density at $700 \mathrm{~nm}$ was recorded using a microplate reader (Platos R, 496. AMP, AMEDA Labordiagnostik GmbH, Graz, Austria). DMSO alone served as the blank (negative control) whereas ascorbic acid served as positive control. The reducing power of the test samples corresponds to $\mu \mathrm{g} / \mathrm{mg}$ dry weight of ascorbic acid equivalent antioxidant capacity ( $\mu \mathrm{g}$ AAE/mg DW).

\subsection{Free Radical Scavenging Assay (FRSA)}

2,2-diphenyl 1-picrylhydrazyl (DPPH) radicals were used in order to evaluate the antioxidant potency of NPs. To a volume of $180 \mu \mathrm{L}$ of DPPH solution (at a concentration of $2.35 \mathrm{mg} / 100 \mathrm{~mL}$ in methanol), $20 \mu \mathrm{L}$ of the diluted NPs test sample were added. The stock solutions $(4 \mathrm{mg} / \mathrm{mL}$ dissolved in DMSO) were further diluted in DMSO to a final volume of $100 \mu \mathrm{L}$ in order to reach the final concentrations of 7.40, 22.22, 66.66, and $200 \mu \mathrm{g} / \mathrm{mL}$ used for this assay. Optical density at $515 \mathrm{~nm}$ was recorded for each test sample with the help of a microplate reader (Platos R, 496. AMP, AMEDA Labordiagnostik GmbH, Graz, Austria) once the incubation $\left(37^{\circ} \mathrm{C}\right.$ for $30 \mathrm{~min}$ ) was completed. To calculate the percent of free radical scavenging assay (FRSA), the following formula was utilized:

$$
\% \text { FRSA }=(1-\mathrm{Abs} / \mathrm{Abc}) \times 100
$$

where $\mathrm{Abc}$ and Abs are the negative control and sample absorbance respectively. The absorbance of DPPH was 1. The ascorbic acid used in this assay served as the positive control. Values of IC50 calculated for each sample showed significant radical scavenging efficiency. The values were 50\% greater and calculated using the two-fold serial dilution method.

\subsection{1. $\alpha$-Amylase Inhibition Assay}

The in vitro $\alpha$-amylase inhibitory activity was determined following the previous standard protocol with slight modifications [43]. Reaction mixture was prepared by mixing $25 \mu \mathrm{L} \alpha$-amylase, $10 \mu \mathrm{L}$ of NPs stock solutions ( $4 \mathrm{mg} / \mathrm{mL}$ in DMSO), $40 \mu \mathrm{L}$ starch solution in $(2 \mathrm{mg} / \mathrm{mL})$ and $15 \mu \mathrm{L}$ phosphate buffer ( $\mathrm{pH}$ 6.8). Starch solution was prepared in potassium phosphate buffer. The resulting mixture was subjected to $30 \mathrm{~min}$ incubation at $50{ }^{\circ} \mathrm{C}$ in the 96 -well plate. A total of $20 \mu \mathrm{L} \mathrm{HCl}(1 \mathrm{M})$ was used for halting the reaction, followed by the addition of $90 \mu \mathrm{L}$ iodine reagent, prepared by mixing $5 \mathrm{mM}$ potassium iodide and $5 \mathrm{mM}$ iodine (in phosphate buffer). The mixture of phosphate buffer with DMSO instead of enzyme and NPs respectively served as the blank (negative control). Acarbose $(250 \mu \mathrm{M})$ served as the positive control. Absorbance was recorded at $540 \mathrm{~nm}$ using a microplate reader 
(Platos R, 496. AMP, AMEDA Labordiagnostik GmbH, Graz, Austria). The activity was expressed as a percentage of $\alpha$-amylase inhibition. The following equation was used for calculation:

$$
\% \alpha-\text { amylase inhibition }=(\mathrm{As}-\mathrm{An}) /(\mathrm{Ab}-\mathrm{An}) \times 100
$$

where As = sample's absorbance, $\mathrm{An}=$ negative control's absorbance and Ab = blank's absorbance.

\subsection{Brine Shrimp Lethality Assay}

Synthesized NPs $(20 \mathrm{mg} / \mathrm{mL}$ stock in water) were tested for probable lethality in the 96-well plate $(300 \mu \mathrm{L})$ for $24 \mathrm{~h}$ against Artemia salina (brine shrimp). Brine shrimp is well-known in study of the toxicological effect of a substance on living organisms [42]. Larvae of Artemia salina was used for this purpose following protocols described by [42]. The eggs of brine shrimp were subjected to incubation for a period of $24-48 \mathrm{~h}$ for hatching. During the process, constant oxygen supply in sterile sea water $(38 \mathrm{~g} / \mathrm{L})$ was ensured. Sterile sea water was supplemented with $6 \mathrm{mg} / \mathrm{L}$ dried yeast in a specifically designed plastic tray with two-compartments under proper illumination. Illumination provides the necessary light and temperature $\left(30-32{ }^{\circ} \mathrm{C}\right)$ for hatching. A total of 10 mature nauplii (phototropic) were picked using Pasteur pipette and introduced into the wells. The required volume, as described in developed previous protocols, of the test extracts contain 1\% DMSO in sea water. The final concentrations of NPs were adjusted to 25,50,100, and $200 \mu \mathrm{g} / \mathrm{mL}$ before transferring it to the wells containing shrimp larvae and sea water. A volume of $300 \mu \mathrm{L}$ was adjusted in each well. Serial concentrations of doxorubicin (ranging from 1 to $10 \mu \mathrm{g} / \mathrm{mL}$ ) were taken as the positive control while that of the DMSO (1\%) in sea water served as the negative control. After an incubation period of $24 \mathrm{~h}$, live shrimps were quantified and median lethal concentration (LC50) was determined by using the table curve 2D v5.01 of the test extracts with $\geq 50 \%$ mortality. Doxorubicin was used because it is a renowned chemotherapeutic agent used for a variety of cancer treatments [44].

\subsection{Compatibility with Isolated Human Red Blood Cells (hRBCs)}

Hemolytic assay was performed so as to assess the bio-safe nature of the synthesized $\mathrm{ZnO}$ NPs against freshly isolated human red blood cells. The fresh blood samples were collected from 2 male and 1 female (average age 28 years) healthy students, having no medical history with sterile syringes. All procedure performed in the study involving human participants were in accordance with the ethical standards of the International and National Research Committees and with the 1964 Helsinki Declaration and its later amendments. Informed consent was obtained from all participants involved in this study. In order to prevent blood clotting, the blood was dispensed in an EDTA tube [45]. To isolate the red blood cells, $1 \mathrm{~mL}$ blood was centrifuged at 14,000 rpm for $5 \mathrm{~min}$. About 9.8 mL of PBS (phosphate-buffer saline) ( $\mathrm{pH}$ : 7.2) was introduced into $200 \mu \mathrm{L}$ of pelleted erythrocyte, followed by shaking in PBS. Approximately $100 \mu \mathrm{L}$ of the test NP solution and erythrocyte suspension were added to a $1.5 \mathrm{~mL}$ Eppendorf tube. The resulting tubes were then incubated for $1 \mathrm{~h}$ at $35^{\circ} \mathrm{C}$ followed by centrifugation at 10,000 rpm for $10 \mathrm{~min}$. The supernatant thus obtained was collected and dispensed $(100 \mu \mathrm{L})$ in a 96-well plate and the release of hemoglobin was assessed using a BioTek ELX800 Absorbance Microplate Reader (BioTek Instruments, Colmar, France) at $540 \mathrm{~nm}$. The positive and negative controls in this study were Triton X-100 and DMSO respectively. The results correspond to the percent hemolysis brought about by NP dilution using the following formula:

$$
\begin{gathered}
\% \text { Hemolysis }=\left[\text { Sample }_{\mathrm{Abs}}-\mathrm{Negative} \text { control }_{\mathrm{Abs}} /{\text { Positive } \text { control }_{\mathrm{Abs}}-\text { Negative }}_{\text {control } \left._{\mathrm{Abs}}\right] . \times 100}\right.
\end{gathered}
$$




\subsection{Statistical Analysis}

Statistically, all of the results evaluated for assays were evaluated using one-way variance (ANOVA) analysis followed by Duncan's and Tukey test using PASW Statistics 18. $p<0.01, p<0.001$ or $p<0.05$ was deemed significant when appropriate. Data was expressed in terms of mean \pm SD.

\section{Results}

ZnO NPs were successfully prepared via different plant sources such as wild plant, in vitro derived plantlets, seeds, and callus cultures by simple co-precipitation. All of the NPs, i.e., seed extract mediated ZnO NPs (S-ZNPs), in vitro derived plantlets extract mediated ZnO NPs (P-ZNPs), wild plant extract mediated ZnO NPs (W-ZNPs) and callus extract mediated ZnO NPs (C-ZNPs) were characterized through various techniques such as powdered XRD, FTIR, SEM and TGA.

\subsection{XRD Analysis}

Powder XRD was employed to verify the crystallinity and phase distribution of the synthesized ZnO NPs. Figure 1 shows XRD pattern of W-ZNPs (Figure 1a), P-ZNPs (Figure 1b), C-ZNPs (Figure 1c) and S-ZNPs (Figure 1d). The peaks for W-ZNPs were recorded at 31.6768, 34.2977, 36.2065, 47.3166, 56.4356, 62.7896, 67.8602 and 68.946. The peaks for S-ZNPs were recorded at 31.7122, 34.3859, 36.147, 47.4947, 56.5241, 62.8238, 66.2066, 67.9154, 69.1088 and 76.9091. C-ZNPs showed peaks at 31.5134, 34.2325, 36.0115, 47.3725, 56.3484, 62.5803, 67.8055 and 68.9589. P-ZNPs showed peaks at 31.682, 34.3597, 36.1419, 47.3757, 56.492, 62.7547, 66.2668, 67.8583, 69.0672, 72.438 and 76.8551. The sizes of ZnO NPs calculated using the Scherrer equation were 44.06, 30.8, 44 and $46 \mathrm{~nm}$ synthesized respectively for W-ZNPs, P-ZNPs, C-ZNPs and S-ZNPs, respectively.
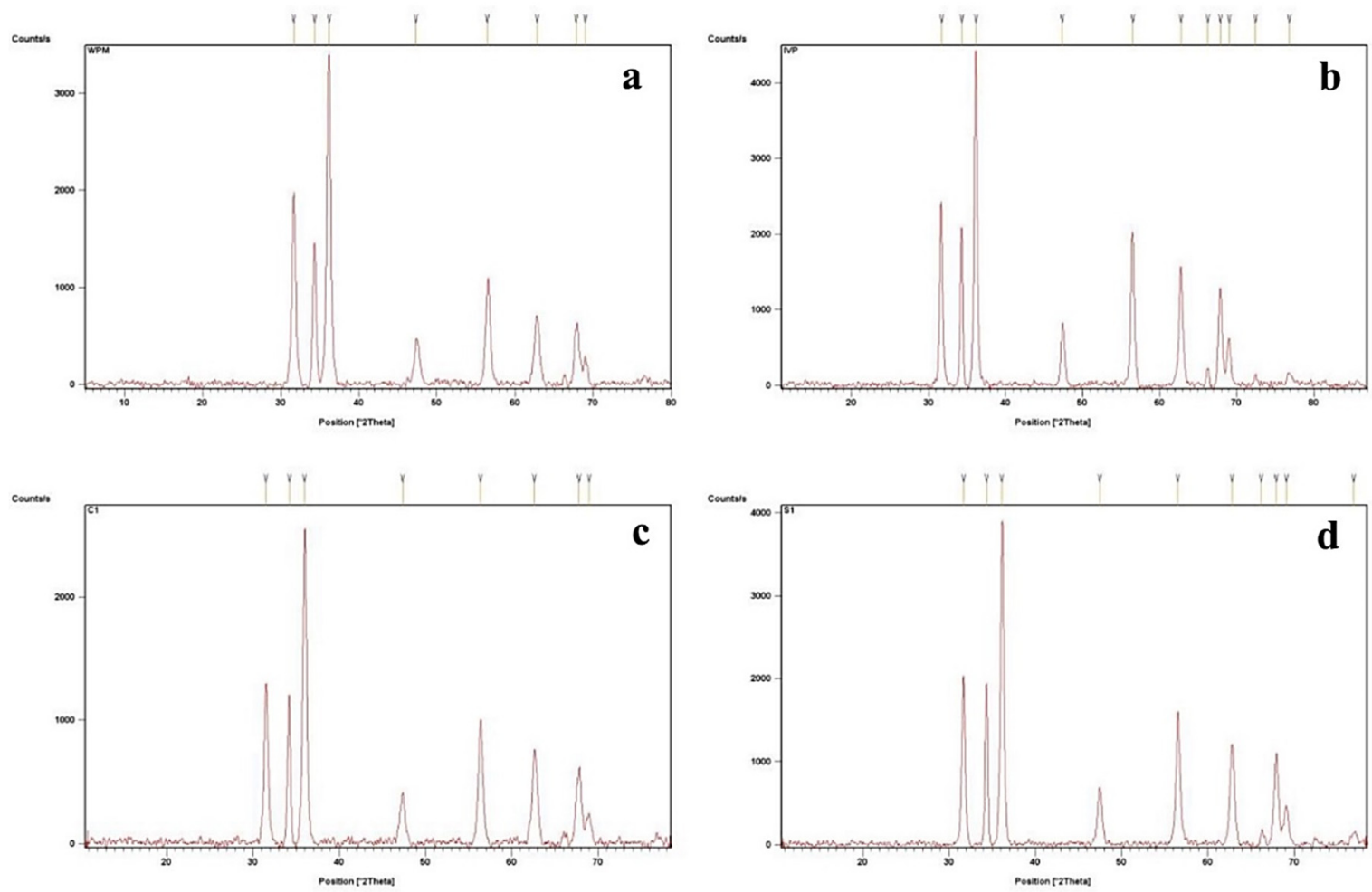

Figure 1. X-ray diffraction analysis of (a) wild plant extract mediated ZnO nanoparticles (NPs) (W-ZNPs), (b) in vitro derived plantlets extract mediated ZnO NPs (P-ZNPs), (c) callus extract mediated ZnO NPs (C-ZNPs) and (d) seed extract mediated ZnO NPs (S-ZNPs). 


\subsection{Scanning Electron Microscopy}

Size and surface morphology of the prepared ZnO NPs were imaged through SEM analysis. Figure 2 displays SEM images of W-ZNPs (Figure 2a), P-ZNPs (Figure 2b), C-ZNPs (Figure 2c) and S-ZNPs (Figure 2d). Flower-like morphology was observed for W-ZNPs, C-ZNPs and S-ZNPs. In the case of P-ZNPs, small petal-like structures attached to form a flower-shaped morphology with irregular shapes. The average size of ZnO NPs evaluated from SEM analysis were 61.3, 51.7,64 and $61.9 \mathrm{~nm}$ synthesized for W-ZNPs, P-ZNPs, C-ZNPs and S-ZNPs, respectively. Considering the precision of SEM, we observe that these sizes are in a close proximity with those calculated using the Scherrer equation following XRD analysis, and therefore, confirm it.
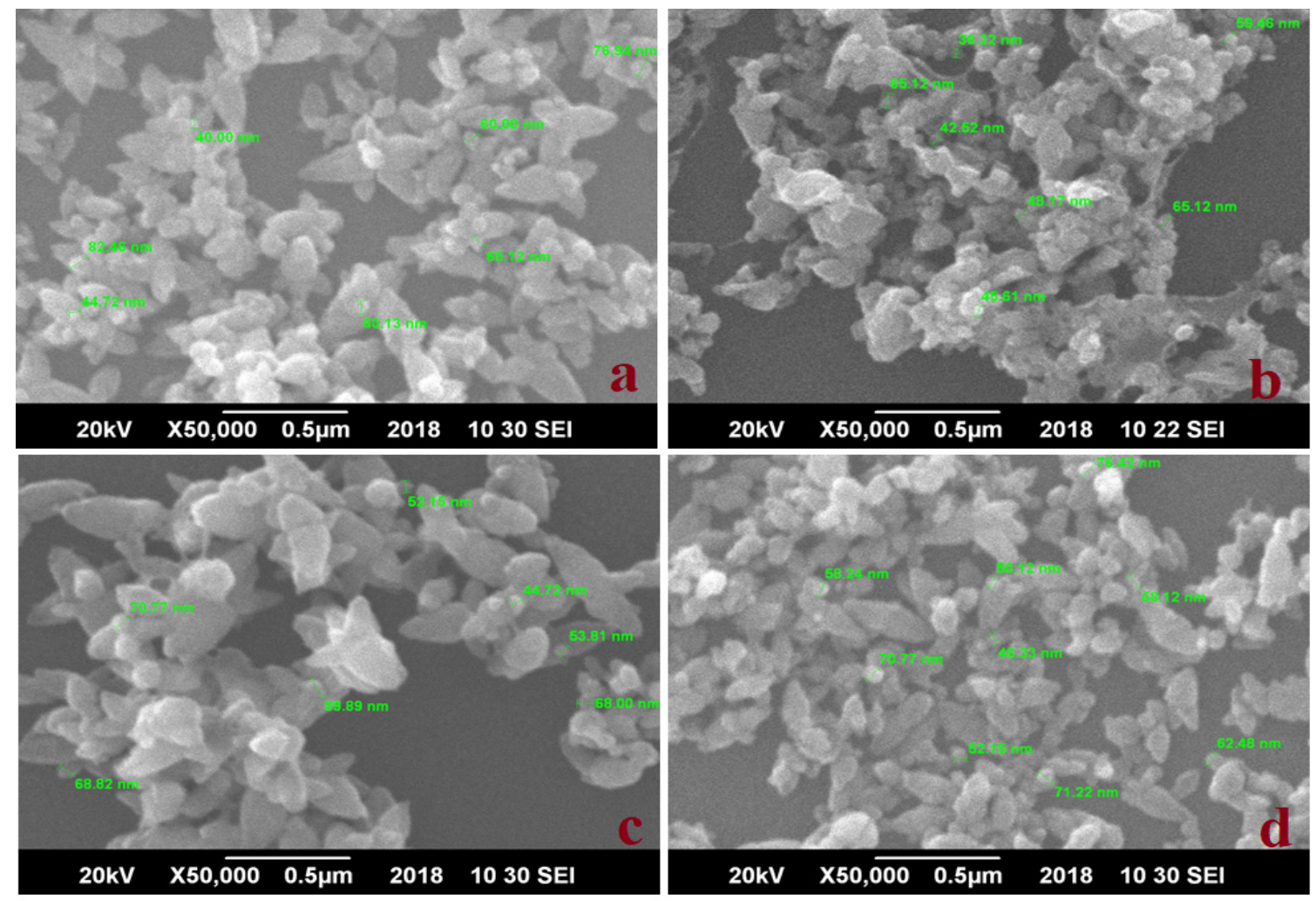

Figure 2. SEM images of (a) W-ZNPs, (b) P-ZNPs, (c) C-ZNPs and (d) S-ZNPs.

\subsection{FT-IR Analysis}

Fourier transform infrared spectroscopy was performed in order to access the involvement of biological molecules towards the formation of ZnO NPs. The results illustrate significant absorption spectra ranging from 400 to $4000 \mathrm{~cm}^{-1}$ (Figure 3). In all four FT-IR spectrums, i.e., W-ZNPs (a), P-ZNPs (b), C-ZNPs (c) and S-ZNPs (d), there is an absorption band at 518, 516, 516 and $516 \mathrm{~cm}^{-1}$ which is the characteristic signal of the $\mathrm{Zn}-\mathrm{O}$ bonding, verifying that the prepared material was indeed $\mathrm{ZnO}$ [21]. Moreover, the peaks at 1633 and $1637 \mathrm{~cm}^{-1}$ in the case of P-ZNPs and S-ZNPs and peaks at 1336, 1396 and $1400 \mathrm{~cm}^{-1}$ in P-ZNPs, W-ZNPs and C-ZNPs were obtained as a result of aromatic rings, and their functional groups exist in the plant sources used [22]. Peaks obtained in the region of 3286 to 3290 and 1051 to $1058 \mathrm{~cm}^{-1}$ in all four FTIR spectrums are attributed to C-H and C-O-C stretching [46] and peaks at $2360 \mathrm{~cm}^{-1}$ are due to $C=C$ stretching vibrations. These results illustrate the possible role of biological molecules in the fabrication of ZnO NPs. 
a
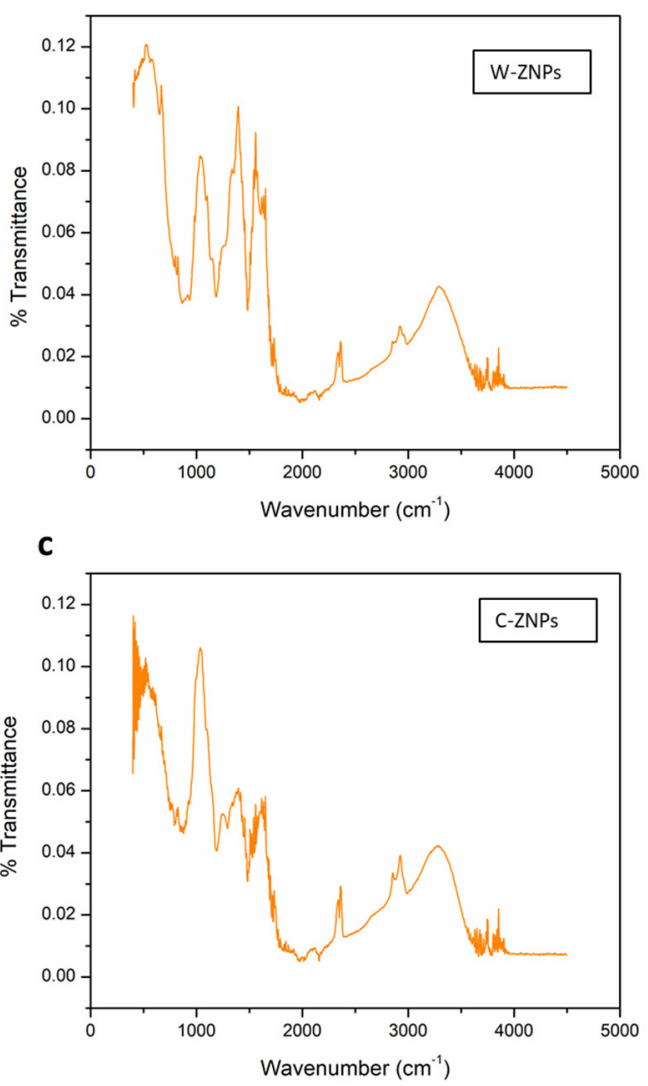

b

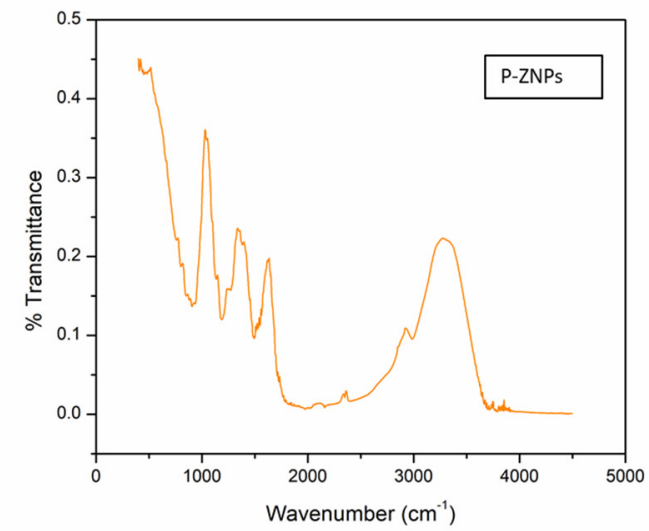

d

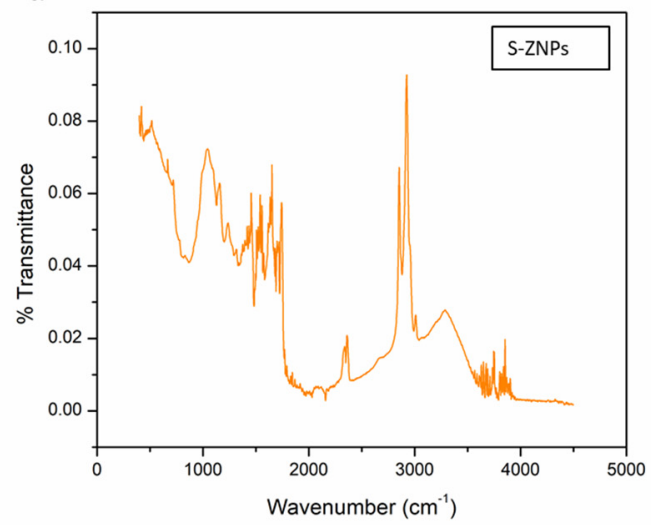

Figure 3. FTIR spectral analysis of (a) W-ZNPs, (b) P-ZNPs, (c) C-ZNPs and (d) S-ZNPs.

\subsection{Thermogravimetric Analysis (TGA)}

The thermal stability of the green synthesized NPs $(20 \mathrm{mg})$ was evaluated via TGA by subjecting the NPs to a temperature in the range of $0-1100{ }^{\circ} \mathrm{C}$ (Figure 4). Initial weight loss in W-ZNPs, C-ZNPs, P-ZNPs and S-ZNPs was observed at $134^{\circ} \mathrm{C}, 137^{\circ} \mathrm{C}, 138^{\circ} \mathrm{C}$ and $141{ }^{\circ} \mathrm{C}$ respectively, which is attributed to the loss of moisture. The second major decomposition of the four samples occurred between $220^{\circ} \mathrm{C}$ and $350{ }^{\circ} \mathrm{C}$. The third major weight loss occurred at a high temperature, $\geq 720^{\circ} \mathrm{C}$. The loss of weight in this event was $\sim 22 \%, \sim 23 \%, \sim 23 \%$ and $\sim 24 \%$, respectively.

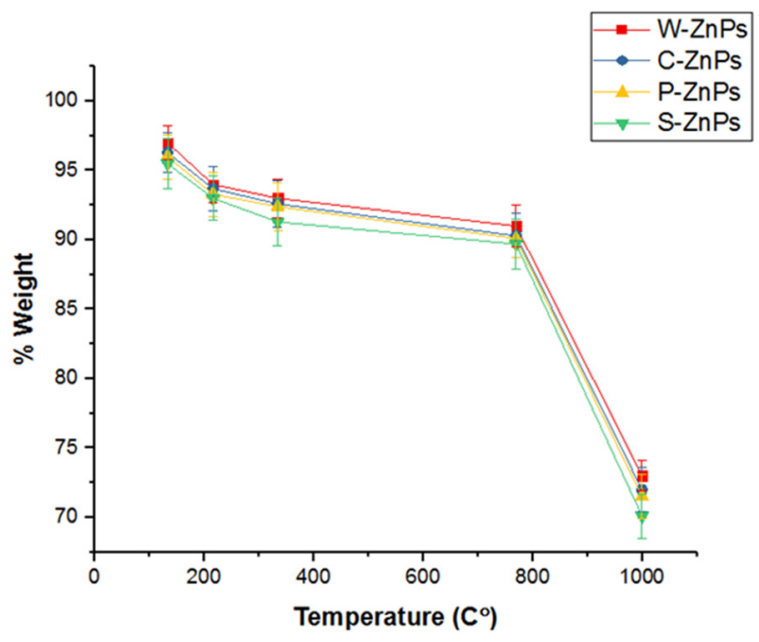

Figure 4. Thermal stability of ZnO NPs at different temperatures. The experiment was carried out in triplicate. The values given in figure are mean \pm standard deviation of the original data. 


\subsection{Antibacterial Activities}

Antibacterial assay was performed against both gram-positive and gram-negative bacterial strains (Figure 5). All of the NPs showed considerable antibacterial potency against the tested strains (S. aureus, B. subtilis, K. pneumonia, P. aeruginosa and E. coli).
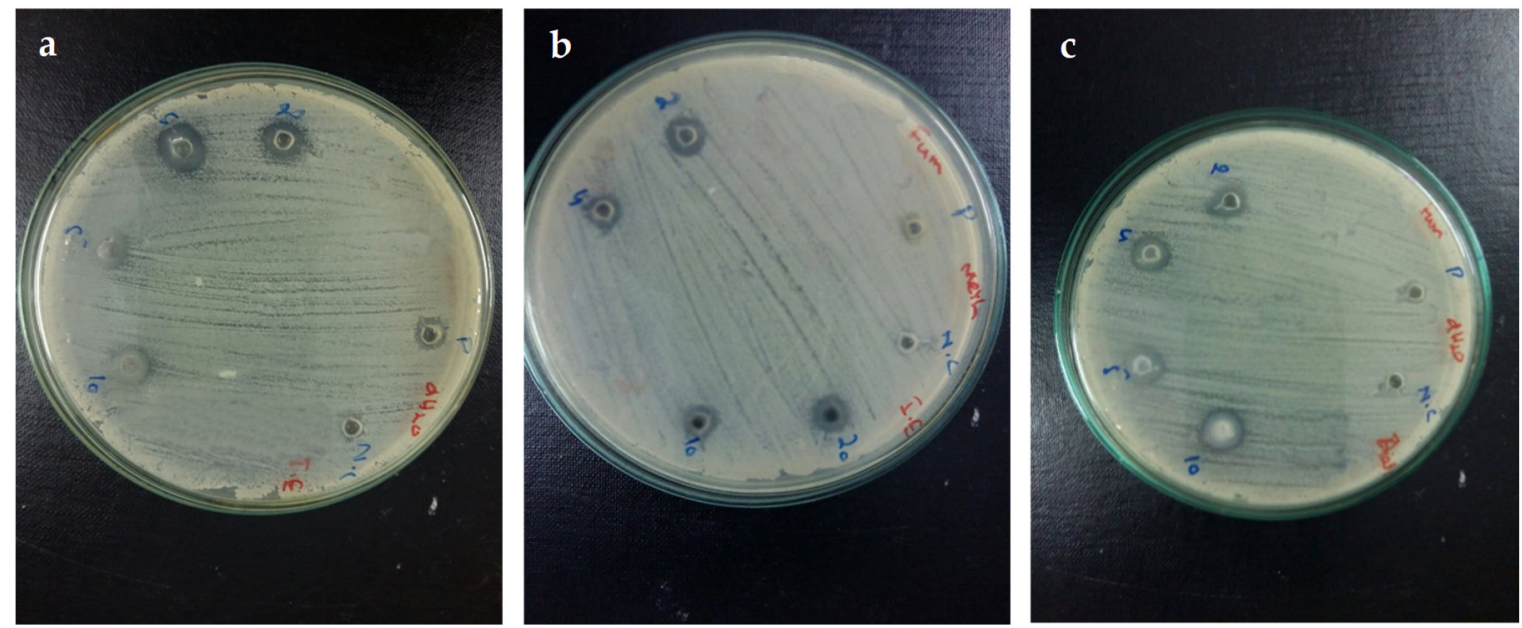

Figure 5. NPs activity against (a) S. aureus, (b) K. pneumonia, (c) P. aeruginosa. The experiments were carried out in triplicate. The values given in Table 1, expressed as mean \pm standard deviation of the original data.

Samples showing the zone of inhibition, $\geq 12 \mathrm{~mm}$, to be considered as significantly active. The data obtained was further processed to appraise MIC through broth micro dilution method. Among all of the tested strains, S. aureus was found to be the most susceptible bacterial strain with maximum zone of inhibition against S-ZNPs $(20 \pm 0.98 \mathrm{~mm})$ with a MIC of $\geq 100 \mu \mathrm{g} / \mathrm{mL}$. C-ZNPs proved most potent against K. pneumoniae $(17 \pm 1.11 \mathrm{~mm})$ having a MIC of $\geq 100 \mu \mathrm{g} / \mathrm{mL}$. B. subtilis and E. coli showed maximum susceptibility towards W-ZNPs $(9 \pm 0.60 \mathrm{~mm}$ and $10 \pm 0.75 \mathrm{~mm}$, respectively. P-ZNPs proved to be most potent against $P$. aeruginosa showing a maximum zone of inhibition $(17 \pm 0.78 \mathrm{~mm})$. Overall, S-ZNPs proved to be the most potent antibacterial agents, showing clear zones of inhibition $(20 \pm 0.98 \mathrm{~mm}, 8 \pm 0.58 \mathrm{~mm}, 15 \pm 0.93 \mathrm{~mm}, 13 \pm 0.54 \mathrm{~mm}$ and $7 \pm 0.92 \mathrm{~mm}$ respectively) against S. aureus, B. subtilis, K. pneumonia, P. aeruginosa and E. coli. Cefixime served as positive control for K. Pneumoniae, P. aeruginosa and E-coli while Roxithromycin served as positive control for S. aureus and B. subtilus. DMSO served as negative control during the analysis. Figure 5 shows the zones of inhibition against the bacterial strains, while the measured growth inhibitory zones and MIC of various samples is given in Table 1 . These results are in the range of previous work dealing with the antibacterial activity of biosynthesized ZnO NPs [47-51].

Table 1. Zones of inhibition (expressed in $\mathrm{mm}$ ) and minimum inhibitory concentrations (MICs) (expressed in $\mu \mathrm{g} / \mathrm{mL}$ ) of the synthesized NPs against various bacterial strains.

\begin{tabular}{|c|c|c|c|c|c|c|c|c|c|}
\hline \multirow{2}{*}{$\frac{\text { Samples }}{\text { C-ZNPs }}$} & \multicolumn{2}{|c|}{ S. aureus } & \multicolumn{2}{|c|}{ B. subtilis } & К. рnеuтопia & \multicolumn{2}{|c|}{ P. aeruginosa } & \multicolumn{2}{|l|}{ E. coli } \\
\hline & $16.03 \pm 0.58^{\mathrm{ab}}$ & 33.33 & $7.48 \pm 0.60^{a b}$ & - & $17.66 \pm 1.11^{a}$ & $\geq 10016.28 \pm 0.33^{a}$ & $\geq 100$ & $9.83 \pm 0.47^{\mathrm{a}}$ & - \\
\hline S-ZNPs & $20.55 \pm 0.98^{\mathrm{a}}$ & $\geq 100$ & $8.29 \pm 0.58^{a}$ & - & $15.56 \pm 0.93^{\mathrm{ab}}$ & $-\quad 13.88 \pm 0.54^{b}$ & - & $7.06 \pm 0.92^{a b}$ & - \\
\hline W-ZNPs & $14.85 \pm 1^{\mathrm{b}}$ & 100 & $9.58 \pm 0.60^{\mathrm{a}}$ & - & $15.39 \pm 0.86^{\mathrm{ab}}$ & $-\quad 15.53 \pm 0.66^{\mathrm{ab}}$ & - & $1.07 \pm 0.75^{\mathrm{a}}$ & - \\
\hline positive control & $13.74 \pm 0.7^{b c}$ & & $8.06 \pm 0.7^{a}$ & & $12.32 \pm 0.9^{b}$ & $12.85 \pm 78^{b}$ & & $8.33 \pm 0.7^{\mathrm{ab}}$ & \\
\hline negative control & $8.77 \pm 0.6^{\mathrm{cd}}$ & & $6.65 \pm 0.5^{\mathrm{ab}}$ & & $7.03 \pm 0.6^{c}$ & $7.91 \pm 0.5^{c}$ & & $7.85 \pm 0.6^{\mathrm{ab}}$ & \\
\hline
\end{tabular}

Data is expressed in terms of mean \pm SD. Different letters indicate significant differences between conditions $(p<0.05)$. 


\subsection{Antioxidant In Vitro Capacities}

TAC, DPPH-FRSA and total reducing power (TRP) assays were performed through well-established procedures [52]. The highest TAC was found to be $27.7 \pm 0.9 \mu \mathrm{gAAE} / \mathrm{mg}$ for P-ZNPs followed by C-ZNPs, W-ZNPs and S-ZNPs having TAC of $25.3 \pm 0.7 \mu \mathrm{gAAE} / \mathrm{mg}, 24.3 \pm 0.8 \mu \mathrm{gAAE} / \mathrm{mg}$ and $22.9 \pm 0.9 \mu \mathrm{gAAE} / \mathrm{mg}$, respectively (Figure 6a). TRP assay was also performed to further assess the presence of the antioxidant potential of NPs. The method implicates reductones investigation. These reductones are species with antioxidant potency that are believed to be due to their capacity to donate $\mathrm{H}$-atom. This results in discontinuation of free radical chains [5]. Figure $6 \mathrm{~b}$ shows the TRP of the bio augmented ZnO NPs used at different concentrations. The value of reducing power decreases with the decreased concentration of test samples. The maximum value of reducing power was observed at $200 \mu \mathrm{g} / \mathrm{mL}$, which was $23.8 \pm 0.7 \mu \mathrm{gAAE} / \mathrm{mg}$ for $\mathrm{W}-\mathrm{ZNPs}$ followed by $18.6 \pm 0.9 \mu \mathrm{gAAE} / \mathrm{mg}$ for S-ZNPs, $14.3 \pm 0.8 \mu \mathrm{gAAE} / \mathrm{mg}$ for C-ZNPs and $12.5 \pm 0.7 \mu \mathrm{gAAE} / \mathrm{mg}$ for P-ZNPs. The least reducing potential of $2.83 \pm 1.43 \mu \mathrm{gAAE} / \mathrm{mg}$, $2.40 \pm 2.1 \mu \mathrm{gAAE} / \mathrm{mg}, 2.19 \pm 1.62 \mu \mathrm{gAAE} / \mathrm{mg}$, and $2.31 \pm 2.02 \mu \mathrm{gAAE} / \mathrm{mg}$ was recorded at $12.5 \mu \mathrm{g} / \mathrm{mL}$ concentration of synthesized NPs. ZnO NPs were subjected to DPPH radical scavenging assay to further confirm the antioxidant potency of biosynthesized ZnO NPs. DPPH assay relies on creation of a light yellow diphenyl picrylhydrazine molecule formed as a result of the reduction of the DPPH moiety after it accepts the electron from a donor species [53]. Moderate DPPH radical scavenging was found at elevated concentrations, i.e., $200 \mu \mathrm{g} / \mathrm{mL}$, which was $12.7 \pm 0.7 \%, 13.6 \pm 0.9 \%, 27.8 \pm 1.3 \%$ and $14.0 \pm 0.9 \%$ for S-ZNPs, W-ZNPs, C-ZNPs and P-ZNPs, while no radical scavenging is testified at lowest concentration $(12.5 \mu \mathrm{g} / \mathrm{mL})$. From the results summarized in Figure $6 \mathrm{c}$, it can be proposed that some of the compounds involved in the stabilization and reduction of NPs during the synthesis process via aqueous extracts of $S$. marianum were of antioxidant nature.
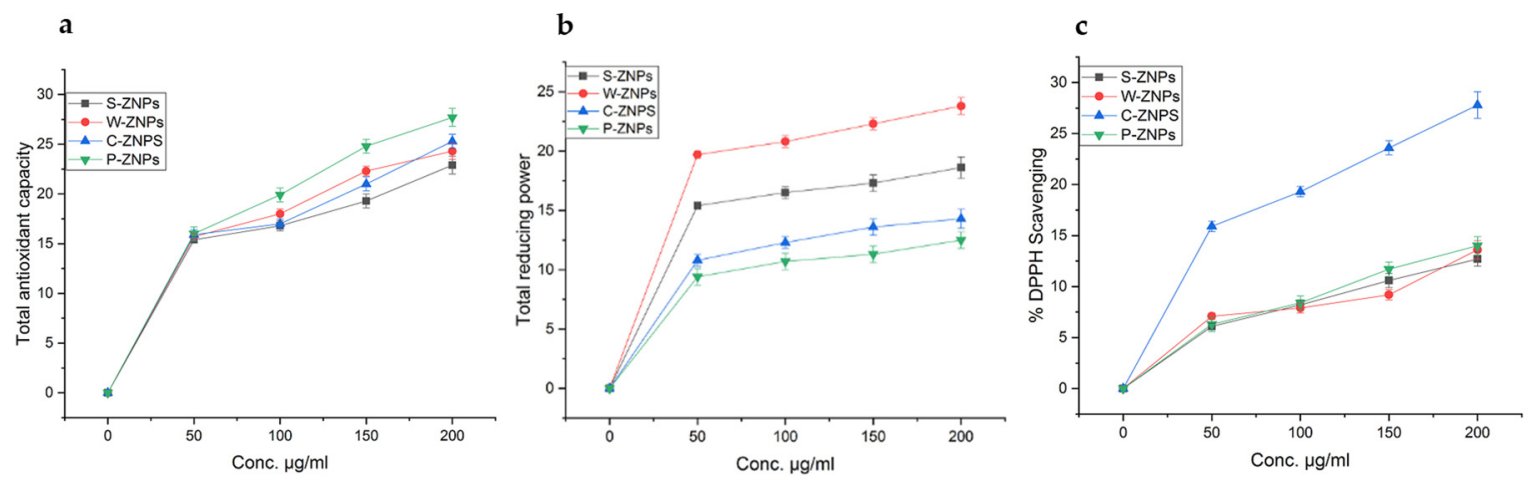

Figure 6. Total antioxidant capacity (TAC) (a), total reducing power (TRP) (b) and DPPH-free radical scavenging assay (FRSA) (c) potential of the biosynthesized ZnO NPs. The experiments were carried out in triplicate. The values given in figure are mean \pm standard deviation of the original data.

\section{7. $\alpha$-Amylase In Vitro Inhibition Potential}

The inhibition of key enzymes, such as $\alpha$-amylase, which is responsible for hydrolysis of carbohydrates, is an effective strategy to maintain blood glucose levels within the permissible range, which is crucial in human pathologies such as diabetes mellitus [47]. In the current study, the $\alpha$-amylase inhibition potential of ZnO NPs was evaluated in vitro at moderate concentration (i.e., $200 \mu \mathrm{g} / \mathrm{mL}$ ). Percent inhibition of $\alpha$-amylase is given in Figure 7. Among the particles, C-ZNPs showed the highest inhibition potential of $22 \%$ followed by S-ZNPs and W-ZNPs with inhibition at $18 \%$ and $16 \%$, respectively. However, P-ZNPs displayed the lowest $\alpha$-amylase inhibition potential (ca 5\% amylase inhibition). The different inhibition potentials of the ZnO NPs may be due to their different physicochemical and morphological features resulting from the plethora of reducing and capping agents in the corresponding extracts [54]. 


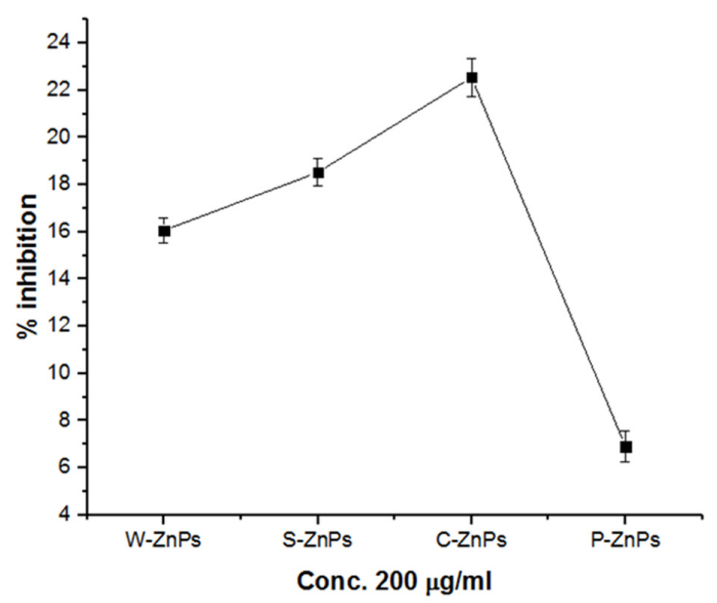

Figure 7. ZnO NPs induced \% inhibition of $\alpha$-amylase. The experiments were carried out in triplicate. The values given in figure are mean \pm standard deviation of the original data.

\subsection{Antiproliferative/Cytotoxic Activity against HepG2 Cancer Cells}

The antiproliferative/cytotoxicity analysis of the synthesized ZnO NPs $(20 \mathrm{mg} / \mathrm{mL}$ stock in water) against HepG2 cell lines was evaluated using MTT assay. From the results, it is clear that all samples showed high cytotoxicity towards non-treated HepG2 cells. The percent viability of the non-treated cells (NTCs) was observed to be $100.90 \pm 5.30 \%$ of viable cells, which dropped to $22.88 \pm 1.58 \%$ of viable cells in the presence of S-ZNPs. Maximum antiproliferative/cytotoxic effect was observed in the presence of W-ZNPs and C-ZNPs (13.16 $\pm 1.83 \%$ and $13.10 \pm 2.83 \%$ of viable cells respectively) at $100 \mu \mathrm{g} / \mathrm{mL}$ dose. P-ZNPs also showed considerable cytotoxicity (20.12 \pm 1.05$)$ against HepG2 cancer cell lines. Figure 8 displays the results of the MTT assay. The results are summarized in Table 2. The lower the values, the higher the effectiveness against liver cancer cells. Our results are similar to previous work [45].
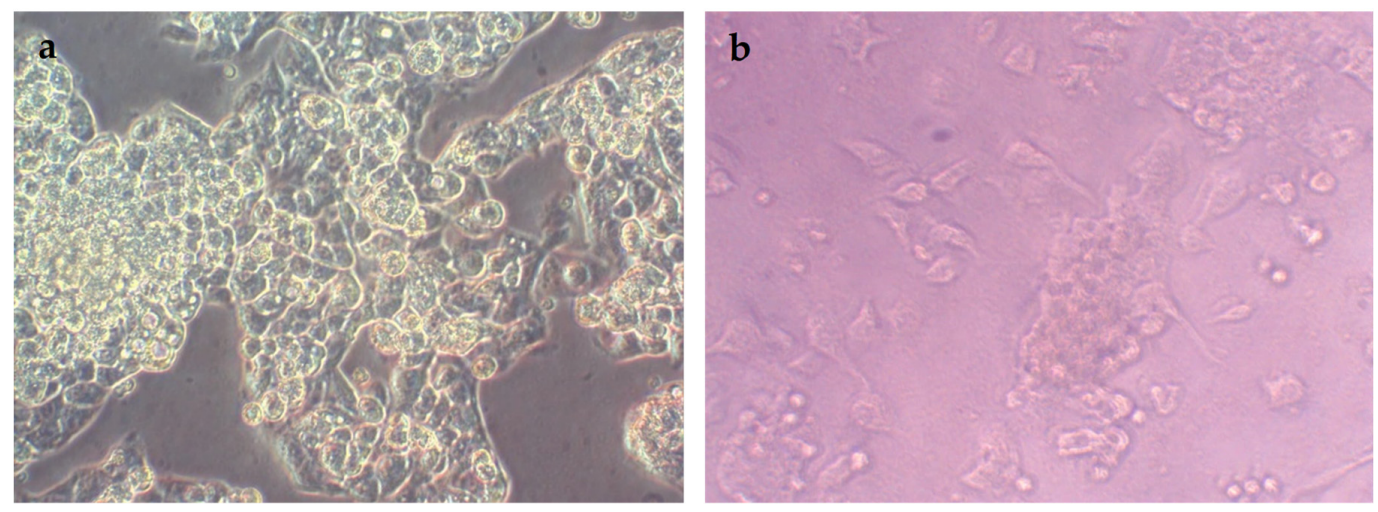

Figure 8. Characteristic pictures of non-treated (a) and treated (b) NPs activity against HepG2 cell line.

Table 2. Viability of human hepatocellular carcinoma (HepG2) cells treated with the different NPs.

\begin{tabular}{cc}
\hline Sample & \% Viability (Mean \pm SD) \\
\hline NTC & $100.90 \pm 5.30^{\mathrm{c}}$ \\
W-ZNPs & $13.16 \pm 1.83^{\mathrm{a}}$ \\
C-ZNPs & $13.10 \pm 2.83^{\mathrm{a}}$ \\
S-ZNPs & $22.88 \pm 1.58^{\mathrm{ab}}$ \\
P-ZNPs & $20.12 \pm 1.05^{\mathrm{ab}}$
\end{tabular}

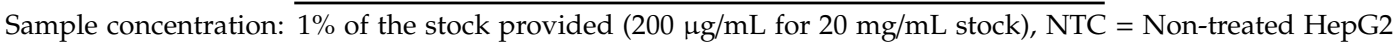
cells; $\mathrm{SD}=$ Standard deviation. The experiments were carried out in triplicate. The values given in the table are mean \pm standard deviation of the original data. Different letters indicate significant differences between conditions $(p<0.05)$. 


\subsection{Brine Shrimp Lethality Assay}

Artemia salina larvae (brine shrimps) were used in order to assess the toxicological effect of samples. Indeed, brine shrimp is a well-known model to study the toxicological effect of a substance on living organisms [42]. Here, we used doxorubicin as a control because it is a renowned chemotherapeutic agent already used for a variety of cancer treatments [44]. All of the samples evaluated for toxic effect against brine shrimps' larvae were found to be significant. The results of all of the samples screened against $A$. salina larvae are summarized in Table 3 . In our hands, doxorubicin during the assay presented an $\mathrm{LC}_{50}$ value of $5.92 \mu \mathrm{g} / \mathrm{mL}$, while among the four NPs samples, the C-ZNPs and P-ZNPs were found to be more toxic showing an $\mathrm{LC}_{50}$ of $10.17 \mu \mathrm{g} / \mathrm{mL}$ and $21.06 \mu \mathrm{g} / \mathrm{mL}$ respectively. The concentration of the sample was found to be directly proportional to the degree of lethality. The brine shrimp lethality assay is known to be a suitable tool to evaluate the toxicity of compounds, but it has also been proposed as a good tool to screen pharmacological activities in NPs and their toxicity results can be matched with their reported ethno-pharmacological role. The brine shrimp results were generally interpreted as follows: LC50 < 1.0 $\mu \mathrm{g} / \mathrm{mL}$ for highly toxic compounds; LC50 1.0-10.0 $\mu \mathrm{g} / \mathrm{mL}$ for toxic compounds; LC50 10.0-30.0 $\mu \mathrm{g} / \mathrm{mL}$ for moderately toxic compounds; LC50 30.0-100.0 $\mu \mathrm{g} / \mathrm{mL}$ for mildly toxic compounds, and $>100.0 \mu \mathrm{g} / \mathrm{mL}$ as non-toxic $[42,43]$. Here, the samples were considered as mildly to moderately toxic, with C-ZNPs and P-ZNPs being moderately toxic, whereas S-ZNPs and W-ZNPs being mildly toxic. For comparison, the renowned chemotherapeutic agent doxorubicin, used to cure a variety of cancers, was considered as toxic.

Table 3. Lethality of the synthesized ZnO NPs against brine shrimp.

\begin{tabular}{ccc}
\hline Sample & \% Mortality Rate (at $200 \mu \mathrm{g} / \mathbf{m L ~ N P s})$ & LC $\mathbf{5 0}(\boldsymbol{\mu g} / \mathbf{m L})$ \\
\hline C-ZNPs & $96.6 \pm 0.6^{\mathrm{a}}$ & 10.17 \\
S-ZNPs & $90 \pm 0.6^{\mathrm{b}}$ & 62.5 \\
W-ZNPs & $93.3 \pm 0.6^{\mathrm{ab}}$ & 38.46 \\
P-ZNPs & $96.6 \pm 0.6^{\mathrm{a}}$ & 21.06 \\
\hline
\end{tabular}

The experiments were carried out in triplicates. The values given in table are mean \pm standard deviation of the original data. Different letters indicate significant differences between conditions $(p<0.05)$.

\subsection{Compatibility with Human Red Blood Cells ( $h R B C s$ )}

To further characterize the bio-safe nature of green synthesized NPs, their compatibility with Human Red Blood Cells (hRBCs) was evaluated. The tested NPs are nontoxic to normal cells only. The results are shown in Figure 9. Based on the standards of "American Society for Testing and Materials Designation" any material having $\geq 5 \%$ hemolysis is considered as hemolytic, slightly hemolytic is $2-5 \%$ while nonhemolytic is $\leq 2 \%$ [55]. The hemolysis is measured when the RBC ruptures and the hemoglobin is released upon treatment with NPs $(4 \mathrm{mg} / \mathrm{mL})$. In the current study, it was revealed that all of the ZnO NPs synthesized are only slightly hemolytic, even at a high concentration of $400 \mu \mathrm{g} / \mathrm{mL}$ (which is 2-times the concentration used for the toxicological effect evaluation with the brine shrimp lethality assay). The S-ZNPs showed the least hemolytic potency (2.7\%) followed by P-ZNPs (3.0\%). The other two NPs (C-ZNPs and W-ZNPs) showed hemolytic potency of $3.2 \%$. The results found were in agreement with some other previous reports [56]. 


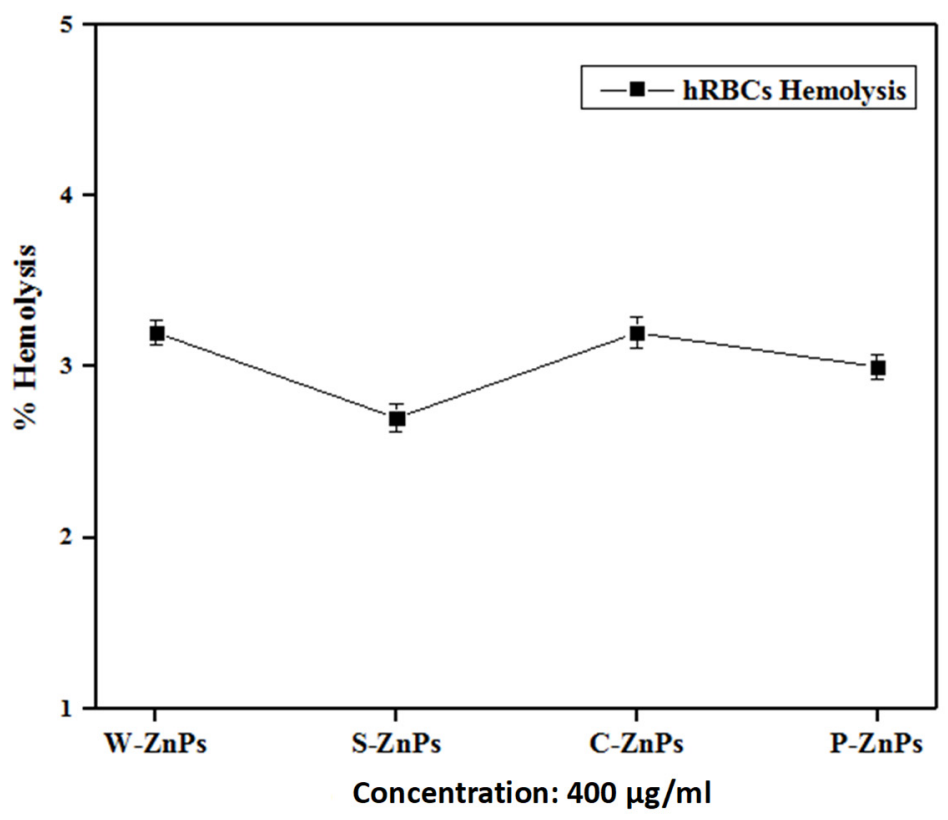

Figure 9. Compatibility of the synthesized ZnO NPs against human red blood cells. The experiments were carried out in triplicates. The values given in figure are mean \pm standard deviation of the original data.

\section{Discussion}

In the present study, different types of ZnO NPs were biologically synthesized from wild green parts (W-ZnPs) and seeds (S-ZnPs) or in vitro callus (C-ZnPs) and plantlets (P-ZnPs) of Silybum marianum. These synthesized NPs were further characterized and various biological assays were performed. The XRD was performed in order to determine the size of the NPs. In the XRD results, the W-ZnPs (Figure 2a) showed various peaks. Highly stable crystalline NPs with size, calculated using Debye Sherrer's equation, ranging between 30.8 and $46.0 \mathrm{~nm}$, were obtained from different tissues of S. marianum.

The diffractions peaks obtained were in strong agreement with hexagonal geometry of ZnO NPs and in agreement with JCPDS No. 79-2205. The narrow and sharp diffraction peaks demonstrated highly crystalline nature of ZnO NPs. Our results are similar to previous results reported $[9,57,58]$. The morphological characterization of NPs was done with SEM analysis. The different types of irregular shapes and morphology were noticed, confirming the synthesis of NPs. Our results are similar with previous work $[9,59]$. The NPs were then checked for stability on high heat using thermogravimetric analyzer. The synthesized NPs breakdown was observed at various temperature starting from $134^{\circ} \mathrm{C}$ to $720^{\circ} \mathrm{C}$. The most stable and heat resistant was S-ZnPs at high temperature. The least stable and resistant was W-ZnPs. The stability of these NPs might be due to the capping agents of S. marianum's various components, such as flavonolignans [60]. The current results are also in harmony with previous reports [61-64].

Following these characterizations, the biological potential of these green bio-assisted synthesized $\mathrm{ZnO}$ NPs were evaluated for various potential pharmaceutical applications. The antibacterial potential of these NPs revealed the highest and lowest antibacterial zones of $20.55 \pm 0.98$ and $7.06 \pm 0.92 \mathrm{~mm}$ was measured in the case of S-ZnPs against S. aureus and E. coli respectively. The enhanced antibacterial activity was due to the high surface to volume ratio, that has previously been proposed [31,58,65-67]. The NPs were further evaluated for various antioxidant mechanisms: the highest total antioxidant capacity was measured for P-ZNPs while the lowest was noted for S-ZnPs; the highest free radical scavenging activity was observed for C-ZnPs and the lowest for S-ZnPs; and finally, the highest total reducing power value was recorded for W-ZNPs while the lowest was for P-ZNPs. These observations match with previous works reporting the high antioxidant potential of plant-based 
NPs $[68,69]$. The in vitro $\alpha$-amylase inhibition assay was performed for all NPs. This key enzyme hydrolyses $\alpha$ bonds of polysaccharides, such as starch and glycogen, yielding glucose and maltose [47]. Reducing its activity through reversible enzymatic inhibition could be an effective strategy to maintain blood glucose level within the permissible range, which is crucial in human pathologies such as diabetes mellitus [47]. Here, the $\mathrm{ZnO} N$ Ps showed a moderate in vitro $\alpha$-amylase inhibition that could be relevant for this form of anti-diabetes strategy. The flavonoids and polyphenols capping of NPs could be involved in the antibacterial, antioxidant and $\alpha$-amylase inhibition potentials of plant-based NPs [70,71]. With S. marianum being a rich source of these compounds, in particular of flavonolignans [60], our results could be in agreement with these previous works. The evaluation of their antiproliferative/cytotoxic activity performed against human hepato-cellular carcinoma cells HepG2 showed the great potential of these green ZnO NPs. This was the case, especially when considering their mild to moderate toxicity revealed by the brine shrimp lethality assay and their bio-safe nature assessed by non-hemolytic against human red blood cells. Further studies are needed to confirm these in vitro assays and characterized the molecular mechanism behind these biological activities, but our present results already sheds light on the great biomedical potential of plant-based NPs, in good agreement with previous reports [72-74].

\section{Conclusions}

NPs have become an indispensable tool for research in the current era owing to their wide array of applications in almost every field. The most widely explored applications, however, are in the field of medical sciences therefore, the current study involves exploitation of NPs synthesized from various parts of Silybum marianum (L.) Gaernt. (Milk thistle) as an antibacterial, antiproliferative/cytotoxic against cancer cells, $\alpha$-amylase inhibitory and antioxidant agents. ZnO NPs were selected for the current study owing to their bio-compatible nature and efficient synthesis protocols. All of the NPs synthesized during the current study showed potent biological activities. S-ZNPs proved to be the most potent antibacterial agent against the tested bacterial species. S-ZNPs were also found to have the most potent antioxidant capacity. C-ZNPs showed a significant antiproliferative/cytotoxic activity against HepG2 human cancer cells. However, C-ZNPs were found to be the most toxic. Nevertheless, these NPs were only mildly to moderately toxic, as revealed by the brine shrimp lethality assay and their bio-safe nature, and hRBC compatibility was assessed by their non-hemolytic action against human red blood cells. These results demonstrated that green $\mathrm{ZnO}$ NPs bio-synthesized using S. marianum plant extracts could be suitable candidates for various future applications in biomedical research.

Author Contributions: Conceptualization, B.H.A. and C.H.; Methodology, M.S. and S.S.H.; Validation, B.H.A. and C.H.; Formal Analysis, B.H.A. and C.H.; Investigation, M.S., S.S.H., M.N., S.N., W.A. and I.U.K.; Resources, B.H.A. and C.H.; Writing-Original Draft Preparation, M.S., S.S.H. and W.A.; Writing-Review and Editing, B.H.A., S.S.H. and C.H.; Visualization, M.S. and S.N.; Supervision, B.H.A. and C.H.; Project Administration, B.H.A. and C.H.; Funding Acquisition, B.H.A. and C.H.

Funding: This research was partly supported the Région Centre-Val de Loire.

Acknowledgments: B.H.A. acknowledges research fellowship of Le Studium-Institute for Advanced Studies, Loire Valley, Orléans, France.

Conflicts of Interest: The authors declare no conflict of interest.

\section{References}

1. Mazzola, L. Commercializing nanotechnology. Nat. Biotech. 2003, 21, 1137-1143. [CrossRef] [PubMed]

2. Wali, M.; Khan, M.A.; Nazir, M.; Siddiquah, A.; Mushtaq, S.; Hashmi, S.S.; Abbasi, B.H. Papaver Somniferum L. mediated novel bioinspired Lead Oxide (Pbo) and Iron Oxide $\left(\mathrm{Fe}_{2} \mathrm{O}_{3}\right)$ nanoparticles: In-vitro biological applications, biocompatibility and their potential towards HEPG2 cell line. Mater. Sci. Eng. C 2019, 103, 109740.

3. Thakkar, K.N.; Mhatre, S.S.; Parikh, R.Y. Biological synthesis of metallic nanoparticles. Nanomedicine 2010, 6, 257-262. [CrossRef] [PubMed] 
4. Kulkarni, N.; Muddapur, U. Biosynthesis of metal nanoparticles: A review. J. Nanotech. 2014, $2014,510246$. [CrossRef]

5. Abdel-Hameed, E.S.S. Total phenolic contents and free radical scavenging activity of certain Egyptian Ficus species leaf samples. Food Chem. 2009, 114, 1271-1277. [CrossRef]

6. Mukherjee, P.; Ahmad, A.; Mandal, D.; Senapati, S.; Sainkar, R.S.; Khan, M.I.; Parishcha, R.; Ajaykumar, P.V.; Alam, M.; Kumar, R.; et al. Fungus-mediated synthesis of silver nanoparticles and their immobilization in the mycelial matrix: A novel biological approach to nanoparticle synthesis. Nano Lett. 2001, 1, 515-519. [CrossRef]

7. Manuela, S.; Adriana, P.; Toloman, D.; Adriana, D.; Lung, I.; Katona, G. Enhanced photocatalytic degradation properties of Zinc Oxide nanoparticles synthesized by using plant extracts. Mater. Sci. Semicond. Proc. 2015, 39, 23-29.

8. Mittal, A.K.; Chisti, Y.; Banerjee, Y.C. Synthesis of metallic nanoparticles using plant extracts. Biotechnol. Adv. 2013, 31, 346-356. [CrossRef] [PubMed]

9. Sangeetha, G.; Rajeshwari, S.; Venckatesh, R. Green synthesis of Zinc Oxide nanoparticles by Aloe barbadensis Miller leaf extract: Structure and optical properties. Mater. Res. Bull. 2011, 46, 2560-2566. [CrossRef]

10. Sharma, D.; Sharma, S.; Kaith, B.S.; Rajput, J.; Kaur, M. Synthesis of ZnO nanoparticles using surfactant free in-air and microwave method. Appl. Surf. Sci. 2011, 257, 9661-9672. [CrossRef]

11. Chen, C.H.; Chang, S.J.; Chang, S.P.; Li, M.J.; Chen, I.C.; Hsueh, T.J.; Hsu, A.D.; Hsu, C.L. Fabrication of a white-light-emitting diode by doping gallium into $\mathrm{ZnO}$ nanowire on a P-gan substrate. J. Phys. Chem. C 2010, 114, 12422-12426. [CrossRef]

12. Hsu, C.L.; Chen, K.C. Improving piezoelectric nanogenerator comprises ZnO nanowires by bending the flexible pet substrate at low vibration frequency. J. Phys. Chem. C. 2012, 116, 9351-9355. [CrossRef]

13. Gao, PX.; Ding, Y.; Wang, Z.L. Crystallographic orientation-aligned ZnO nanorods grown by a tin catalyst. Nano Lett. 2003, 3, 1315-1320. [CrossRef]

14. Hu, Y.; Zhang, Y.; Chang, Y.; Snyder, R.L.; Wang, Z.L. Optimizing the power output of a ZnO photocell by piezopotential. ACS Nano 2010, 4, 4220-4224. [CrossRef] [PubMed]

15. Yang, J.L.; An, S.J.; Park, W.I.; Yi, G.C.; Choi, W. Photocatalysis using ZnO thin films and nanoneedles grown by metal-organic chemical vapor deposition. Adv. Mater. 2004, 16, 1661-1664. [CrossRef]

16. Hsueh, T.J.; Hsu, C.L. Fabrication of gas sensing devices with $\mathrm{ZnO}$ nanostructure by the low-temperature oxidation of zinc particles. Sens. Actuat. B Chem. 2008, 131, 572-576. [CrossRef]

17. Meulenkamp, E.A. Synthesis and growth of ZnO nanoparticles. J. Phys. Chem. 1998, 102, 5566-5572. [CrossRef]

18. Baxter, J.B.; Walker, A.M.; Ommering, K.V.; Aydil, A.S. Synthesis and characterization of ZnO nanowires and their integration into dye-sensitized solar cells. Nanotechnology 2006, 17, S304. [CrossRef]

19. Sheng, Y.; Adiga, N.; Ba, S.; Dasgupta, T.; Wu, C.F.J.; Wang, Z.L. Optimizing and improving the growth quality of $\mathrm{ZnO}$ nanowire arrays guided by statistical design of experiments. ACS Nano 2009, 3, 1803-1812.

20. Jiang, C.Y.; Sun, X.W.; Lo, G.Q.; Kwong, D.L.; Wang, J.X. Improved dye-sensitized solar cells with a ZnO-nanoflower photoanode. Appl. Phys. Lett. 2007, 90, 263501. [CrossRef]

21. Paithankar, V.V.; Raut, K.K.; Charde, R.M.; Vyas, J.V. Phyllanthus Niruri: A magic herb. Res. Pharm. 2011, $1,1-9$.

22. Senthilraja, A.; Subash, B.; Rajamanickam, K.D.; Swaminathan, M.; Shanthi, M. Synthesis, characterization and catalytic activity of co-doped $\mathrm{Ag}-\mathrm{Au}-\mathrm{ZnO}$ for MB dye degradation under UV-A light. Mater. Sci. Semicond. Proc. 2014, 22, 83-91. [CrossRef]

23. Madhumitha, G.; Rajakumar, G.; Roopan, S.M.; Rahuman, A.A.; Priya, K.M.; Saral, A.M.; Khan, F.R.N.; Khanna, V.G.; Velayutham, K.; Jayaseelan, C. Acaricidal, insecticidal and larvicidal efficacy of fruit peel aqueous extract of Annona squamosa and its compounds against blood-feeding parasites. Parasit. Res. 2012, 111, 2189-2199. [CrossRef] [PubMed]

24. Madhumitha, G.; Saral, A.M. Free radical scavenging assay of Thevetia neriifolia leaf extracts. Asian J. Chem. 2009, 21, 2468-2470.

25. Jafarirad, S.; Ardehjani, P.H.; Movafeghi, A. Are the green synthesized nanoparticles safe for environment? A case study of aquatic plant Azolla filiculoides as an indicator exposed to magnetite nanoparticles fabricated using microwave hydrothermal treatment and plant extract. J. Environ. Sci. Health A 2010, 54, 516-527. [CrossRef] 
26. Mohanpuria, P.; Rana, N.K.; Yadav, S.K. Biosynthesis of nanoparticles: Technological concepts and future applications. J. Nanopart. Res. 2008, 10, 507-517. [CrossRef]

27. Khan, M.; Al-Marri, A.H.; Khan, M.; Shaik, M.R.; Mohri, N.; Adil, S.F.; Kuniyil, M.; Alkhathlan, H.Z.; Al-Warthan, A.; Tremel, T.; et al. Green approach for the effective reduction of graphene oxide using Salvadora persica L. root (miswak) extract. Nanoscale Res. Lett. 2015, 10, 281. [CrossRef]

28. Ochiai, S.; Kumar, P.; Santhakumar, K.; Shin, P.K. Examining the effect of additives and thicknesses of hole transport layer for efficient organic solar cell devices. Electron. Mater. Lett. 2013, 9, 399-403. [CrossRef]

29. Kumar, P.; Santhakumar, K.; Tatsugi, J.; Shin, P.-K.; Ochiai, S. Comparison of properties of polymer organic solar cells prepared using highly conductive modified pedot Pss films by spin-and spray-coating methods. Jpn. J. Appl. Phys. 2013, 53, 01AB08. [CrossRef]

30. Saitoh, L.; Babu, R.R.; Kannappan, S.; Kojima, K.; Mizutani, T.; Ochiai, S. Performance of spray deposited poly [N-9'"-hepta-decanyl-2,7-carbazole-alt-5,5-(4',7'-di-2-thienyl-2', 1', 3'-benzothiadiazole)] [6,6]-phenyl-C61-butyric acid methyl ester blend active layer based bulk heterojunction organic solar cell devices. Thin Solid Films. 2012, 520, 3111-3117. [CrossRef]

31. Gunalan, S.; Sivaraj, R.; Rajendran, V. Green synthesized ZnO nanoparticles against bacterial and fungal pathogens. Prog. Nat. Sci. Mater. Int. 2012, 22, 693-700. [CrossRef]

32. Özgür, Ü.; Alivov, Y.I.; Liu, C.; Teke, A.; Reshchikov, M.A.; Doğan, S.; Avrutin, V.; Cho, S.J.; Morkoç, H. A comprehensive review of $\mathrm{ZnO}$ materials and devices. J. Appl. Phys. 2005, 98, 041301. [CrossRef]

33. Djurišić, A.; Chen, B.; Leung, X.; Ng, Y.H. ZnO nanostructures: Growth, properties and applications. J. Mater. Chem. 2012, 22, 6526-6535. [CrossRef]

34. Wang, Z.L. Zinc oxide nanostructures: Growth, properties and applications. J. Phys. Cond. Matt. 2004, 16, R829. [CrossRef]

35. Ali, K.; Dwivedi, S.; Azam, A.; Saquib, Q.; Al-Said, M.S.; Alkhedhairy, A.A.; Musarrat, J. Aloe vera extract functionalized zinc oxide nanoparticles as nanoantibiotics against multi-drug resistant clinical bacterial isolates. J. Colloid. Interface Sci. 2016, 15, 145-156. [CrossRef] [PubMed]

36. Gnanasangeetha, D.; SaralaThambavani, D. One pot synthesis of zinc oxide nanoparticles via chemical and green method. Res. J. Mater. Sci. 2013, 1,1-8.

37. Samat, N.A.; Nor, R.M. Sol-gel synthesis of zinc oxide nanoparticles using Citrus aurantifolia extracts. Ceram. Int. 2013, 39, S545-S548. [CrossRef]

38. Singh, R.P.; Shukla, V.K.; Yadav, R.S.; Sharma, P.K.; Singh, P.K.; Pandey, A.C. Biological approach of zinc oxide nanoparticles formation and its characterization. Adv. Mater. Lett. 2011, 2, 313-317. [CrossRef]

39. Rajiv, P.; Rajeshwari, S.; Venckatesh, R. Bio-fabrication of zinc oxide nanoparticles using leaf extract of Parthenium hysterophorus L. and its size-dependent antifungal activity against plant fungal pathogens. Spectrochim. Acta A Mol. Biomol. Spectrosc. 2013, 112, 384-387. [CrossRef]

40. Beato, V.M.; Orgaz, F.; Mansilla, F.; Montaño, A. Changes in phenolic compounds in garlic (Allium sativum L.) owing to the cultivar and location of growth. Plant Food. Hum. Nutr. 2011, 66, 218-223. [CrossRef]

41. Fatima, H.; Khan, K.; Zia, M.; Ur-Rehman, T.; Mirza, B.; Haq, I.U. Extraction optimization of medicinally important metabolites from Datura innoxia Mill.: An in vitro biological and phytochemical investigation. BMC Complement. Altern. Med. 2015, 19, 376. [CrossRef] [PubMed]

42. Ahmed, M.; Fatima, H.; Qasim, M.; Gul, B.; Haq, IU. Polarity directed optimization of phytochemical and in vitro biological potential of an indigenous folklore: Quercus dilatata Lindl. ex Royle. BMC Complement. Altern. Med. 2017, 17, 386. [CrossRef] [PubMed]

43. Zahra, S.S.; Ahmed, M.; Qasim, M.; Gul, B.; Zia, M.; Mirza, B.; Haq, I.U. Polarity based characterization of biologically active extracts of Ajuga bracteosa Wall. ex Benth. and Rp-HPLC analysis. BMC Complement. Altern. Med. 2017, 17, 443. [CrossRef] [PubMed]

44. Tomankova, K.; Polakova, K.; Pizova, K.; Binder, S.; Havrdova, M.; Kolarova, M.; Kriegova, E.; Zapletalova, J.; Malina, L.; Horakova, J. In vitro cytotoxicity analysis of doxorubicin-loaded/superparamagnetic iron oxide colloidal nanoassemblies on MCF7 and NIH3T3 cell lines. Int. J. Nanomed. 2015, 29, 949-961. [CrossRef] [PubMed]

45. Khalil, A.T.; Ovais, M.; Ullah, I.; Ali, M.; Shinwari, ZK.; Khamlich, S.; Maaza, M. Sageretia thea (osbeck.) mediated synthesis of zinc oxide nanoparticles and its biological applications. Nanomedicine 2017, 12, 1767-1789. [CrossRef] [PubMed] 
46. Saraswathi, V.S.; Tatsugi, J.; Shin, P.K.; Santhakumar, K. Facile biosynthesis, characterization, and solar assisted photocatalytic effect of $\mathrm{ZnO}$ nanoparticles mediated by leaves of L. Speciosa. J. Photochem. Photobiol. B Biol. 2017, 167, 89-98. [CrossRef] [PubMed]

47. Bhuyan, T.; Mishra, K.; Khanuja, M.; Prasad, R.; Varma, A. Biosynthesis of zinc oxide nanoparticles from Azadirachta indica for antibacterial and photocatalytic applications. Mater. Sci. Semicond Process 2015, 32, 55-61. [CrossRef]

48. Dobrucka, R.; Długaszewska, J. Biosynthesis and antibacterial activity of $\mathrm{ZnO}$ nanoparticles using Trifolium pratense flower extract. Saudi J. Biol. Sci. 2016, 23, 517-523. [CrossRef]

49. Elumalai, K.; Velmurugan, S. Green synthesis, characterization and antimicrobial activities of zinc oxide nanoparticles from the leaf extract of Azadirachta indica (L.). Appl. Surf. Sci. 2015, 345, 329-336. [CrossRef]

50. Siddiqi, K.S.; Ur Rahman, A.; Husen, A. Properties of zinc oxide nanoparticles and their activity against microbes. Nanoscale Res. Lett. 2018, 13, 141. [CrossRef]

51. Sirelkhatim, A.; Mahmud, S.; Seeni, A.; Kaus, N.H.M.; Ann, L.C.; Bakhori, S.K.M.; Hasan, H.; Mohamad, D. Review on zinc oxide nanoparticles: Antibacterial activity and toxicity mechanism. Nano-Micro Lett. 2015, 7 , 219-242. [CrossRef] [PubMed]

52. Ul-Haq, I.; Ullah, N.; Bibi, G.; Kanwal, S.; Ahmad, M.S.; Mirza, B. Antioxidant and cytotoxic activities and phytochemical analysis of Euphorbia wallichii root extract and its fractions. Iran. J. Pharm. Res. 2012, 11, 241.

53. Smuleac, V.; Varma, R.; Sikdar, S.; Bhattacharyya, D. Green synthesis of Fe and Fe/Pd bimetallic nanoparticles in membranes for reductive degradation of chlorinated organics. J. Memb. Sci. 2011, 379, 131-137. [CrossRef] [PubMed]

54. Ahmed, D.; Younas, S.; Anwer-Mughal, Q.M. Study of alpha-amylase and urease inhibitory activities of Melilotus indicus (Linn.) All. Pak. J. Pharm. Sci. 2014, 27, 57-61.

55. Aula, S.; Lakkireddy, S.; Swamy, A.V.N.; Kapley, A.; Jamil, K.; Tata, N.R.; Hembram, K. Biological interactions in vitro of zinc oxide nanoparticles of different characteristics. Mater. Res. Exp. 2014, 1, 035041. [CrossRef]

56. Ali, S.S.; Morsy, R.; El-Zawawy, N.A.; Fareed, M.F.; Bedaiwy, M.Y. Synthesized zinc peroxide nanoparticles ( $\mathrm{ZnO}_{2}$-NPs): A novel antimicrobial, anti-elastase, anti-keratinase, and anti-inflammatory approach toward polymicrobial burn wounds. Int. J. Nanomed. 2017, 12, 6059. [CrossRef]

57. Zak, A.K.; Abd Majid, W.H.; Abrishami, M.E.; Yousefi, R. X-ray analysis of ZnO nanoparticles by williamson-hall and size-strain plot methods. Solid State Sci. 2011, 13, 251-256.

58. Senthilkumar, S.R.; Sivakumar, T. Green tea (Camellia Sinensis) mediated synthesis of zinc oxide ( $\mathrm{ZnO})$ nanoparticles and studies on their antimicrobial activities. Int. J. Pharm. Pharm. Sci. 2014, 6, 461-465.

59. Vidya, C.; Hiremath, S.; Chandraprabha, M.N.; Antonyraj, M.A.L.; Gopal, I.V.; Jain, A.; Bansal, K. Green synthesis of $\mathrm{ZnO}$ nanoparticles by Calotropis gigantea. Int. J. Curr. Eng. Technol. 2013, 1, 118-120.

60. Drouet, S.; Abbasi, B.H.; Falguières, A.; Ahmad, W.; Ferroud, C.; Doussot, J.; Vanier, J.; Lainé, E.; Hano, C. Single laboratory validation of a quantitative core shell-based LC separation for the evaluation of silymarin. variability and associated antioxidant activity of pakistani ecotypes of milk thistle (Silybum marianum L.). Molecules 2018, 23, 904. [CrossRef]

61. Matinise, N.; Fuku, X.G.; Kaviyarasu, K.; Mayedwa, N.; Maaza, M. ZnO nanoparticles via Moringa oleifera green synthesis: Physical properties \& mechanism of formation. Appl. Surf. Sci. 2017, 406, 339-347.

62. Nagajyothi, P.C.; An, M.T.N.; Sreekanth, T.V.M.; Lee, J.I.; Lee, D.J.; Lee, K.D. Green route biosynthesis: Characterization and catalytic activity of ZnO nanoparticles. Mater. Lett. 2013, 108, 160-163. [CrossRef]

63. Hameed, S.; Khalil, A.T.; Ali, M.; Numan, M.; Khamlich, S.; Shinwari, Z.K.; Maaza, M. Greener synthesis of $\mathrm{ZnO}$ and $\mathrm{Ag}-\mathrm{ZnO}$ nanoparticles using Silybum marianum for diverse biomedical applications. Nanomedicine 2019, 14, 655-673. [CrossRef] [PubMed]

64. Prasad, C.; Sreenivasulu, K.; Gangadhara, S.; Venkateswarlu, P. Bio inspired green synthesis of $\mathrm{Ni}_{2} / \mathrm{Fe}_{3} \mathrm{O}_{4}$ magnetic nanoparticles using Moringa oleifera leaves extract: A magnetically recoverable catalyst for organic dye degradation in aqueous solution. J. Alloy. Compd. 2017, 700, 252-258. [CrossRef]

65. Jalal, R.; Goharshadi, E.K.; Abareshi, M.; Moosavi, M.; Yousefi, A.; Nancarrow, P. ZnO nanofluids: Green synthesis, characterization, and antibacterial activity. Mater. Chem. Phys. 2010, 121, 198-201. [CrossRef]

66. Ramesh, M.; Anbuvannan, M.; Viruthagiri, G. Green synthesis of ZnO nanoparticles using Solanum nigrum leaf extract and their antibacterial activity. Spectrochim. Acta A Mol. Biomol. Spectrosc. 2015, 136, 864-870. [CrossRef] 
67. Suresh, D.; Nethravathi, P.C.; Rajanaika, H.; Nagabhushana, H.; Sharma, S.C. Green synthesis of multifunctional zinc oxide $(\mathrm{ZnO})$ nanoparticles using Cassia fistula plant extract and their photodegradative, antioxidant and antibacterial activities. Mater. Sci. Semicond. Process. 2015, 31, 446-454. [CrossRef]

68. Nagajyothi, P.C.; Cha, S.J.; Yang, I.J.; Sreekanth, T.V.M.; Kim, K.J.; Shin, H.M. Antioxidant and anti-inflammatory activities of zinc oxide nanoparticles synthesized using Polygala tenuifolia root extract. J. Photochem. Photobiol. B Biol. 2015, 146, 10-17. [CrossRef]

69. Suresh, D.; Shobharani, R.M.; Nethravathi, P.C.; Pavan Kumar, M.A.; Nagabhushana, H.; Sharma, S.C. Artocarpus gomezianus aided green synthesis of $\mathrm{ZnO}$ nanoparticles: Luminescence, photocatalytic and antioxidant properties. Spectrochim. Acta A Mol. Biomol. Spectrosc. 2015, 136, 128-134. [CrossRef]

70. Bala, N.; Saha, S.; Chakraborty, M.; Maiti, M.; Das, S.; Basu, R.; Nandy, P. Green synthesis of zinc oxide nanoparticles using Hibiscus subdariffa leaf extract: Effect of temperature on synthesis, anti-bacterial activity and anti-diabetic activity. RSC Adv. 2015, 5, 4993-5003. [CrossRef]

71. Rajakumar, G.; Thiruvengadam, M.; Mydhili, G.; Gomathi, T.; Chung, I.M. Green approach for synthesis of zinc oxide nanoparticles from Andrographis paniculata leaf extract and evaluation of their antioxidant, anti-diabetic, and anti-inflammatory activities. Bioprocess Biosyst. Eng. 2018, 41, 21-30. [CrossRef] [PubMed]

72. Nagajyothi, P.C.; Sreekanth, T.V.; Tettey, C.O.; Jun, Y.I.; Mook, S.H. Characterization, antibacterial, antioxidant, and cytotoxic activities of $\mathrm{ZnO}$ nanoparticles using Coptidis rhizoma. Bioorg. Med. Chem. Lett. 2014, 24, 4298-4303. [CrossRef] [PubMed]

73. Vijayakumar, S.; Vaseeharan, B.; Malaikozhundan, B.; Shobiya, M. Laurus nobilis leaf extract mediated green synthesis of $\mathrm{ZnO}$ nanoparticles: Characterization and biomedical applications. Biomed. Pharmacother. 2016, 84, 1213-1222. [CrossRef] [PubMed]

74. Prashanth, G.K.; Prashanth, P.A.; Bora, U.; Gadewar, M.; Nagabhushana, B.M.; Ananda, S.; Krishnaiah, G.M.; Sathyananda, H.M. In vitro antibacterial and cytotoxicity studies of $\mathrm{ZnO}$ nanopowders prepared by combustion assisted facile green synthesis. Karbala Int. J. Mod. Sci. 2015, 1, 67-77.

(C) 2019 by the authors. Licensee MDPI, Basel, Switzerland. This article is an open access article distributed under the terms and conditions of the Creative Commons Attribution (CC BY) license (http://creativecommons.org/licenses/by/4.0/). 